\title{
Integrating Blockchain Technology into Healthcare Through an Intelligent Computing Technique
}

\author{
Asif Irshad Khan ${ }^{1, *}$, Abdullah Saad Al-Malaise ALGhamdi ${ }^{2}$, Fawaz Jaber Alsolami ${ }^{1}$, \\ Yoosef B. Abushark ${ }^{1}$, Abdulmohsen Almalawi ${ }^{1}$, Abdullah Marish Ali ${ }^{1}$, Alka Agrawal ${ }^{3}$, \\ Rajeev Kumar ${ }^{4}$ and Raees Ahmad Khan ${ }^{3}$
}

\author{
${ }^{1}$ Department of Computer Science, Faculty of Computing and Information Technology, King Abdulaziz University, \\ Jeddah, 21589, Saudi Arabia \\ ${ }^{2}$ Department of Information Systems, Faculty of Computing and Information Technology, King Abdulaziz University, \\ Jeddah, 21589, Saudi Arabia \\ ${ }^{3}$ Department of Information Technology, Babasaheb Bhimrao Ambedkar University, Lucknow, 226025, Uttar Pradesh, India \\ ${ }^{4}$ Department of Computer Applications, Shri Ramswaroop Memorial University, Barabanki, 225003, Uttar Pradesh, India \\ ${ }^{*}$ Corresponding Author: Asif Irshad Khan. Email: aikhan@kau.edu.sa \\ Received: 20 May 2021; Accepted: 21 June 2021
}

\begin{abstract}
The blockchain technology plays a significant role in the present era of information technology. In the last few years, this technology has been used effectively in several domains. It has already made significant differences in human life, as well as is intended to have noticeable impact in many other domains in the forthcoming years. The rapid growth in blockchain technology has created numerous new possibilities for use, especially for healthcare applications. The digital healthcare services require highly effective security methodologies that can integrate data security with the available management strategies. To test and understand this goal of security management in Saudi Arabian perspective, the authors performed a numerical analysis and simulation through a multi criteria decision making approach in this study. The authors adopted the fuzzy Analytical Hierarchy Process (AHP) for evaluating the effectiveness and then applied the fuzzy Technique for Order of Preference by Similarity to Ideal Solution (TOPSIS) technique to simulate the validation of results. For eliciting highly corroborative and conclusive results, the study referred to a real time project of diabetes patients' management application of Kingdom of Saudi Arabia (KSA). The results discussed in this paper are scientifically proven and validated through various analysis approaches. Hence the present study can be a credible basis for other similar endeavours being undertaken in the domain of blockchain research.
\end{abstract}

Keywords: Blockchain technology; data management; fuzzy logic; AHP; TOPSIS 


\section{Introduction}

Managing healthcare services and their appropriate delivery to the patients is a challenging and complex task. In this league, the practitioners as well as researchers across the world are consistently working on applications to ensure prompt and secure healthcare services for all the stakeholders. However, the big and complex nature of healthcare system poses numerous hurdles for organizations that are trying to deliver quality services with quality systems. In this context, the blockchain technology has emerged as the most efficacious solution for securing healthcare data and preventing breaches [1]. To understand this technology more simply, we can say that it is a simple but effective decentralized data management system [2] which works in a chain pattern with a replica of data over it in parts. Every transaction is checked in the distributed ledger through the consensus of a significant proportion of program members. Whenever and whatever data is entered in such a system may never get deleted. Every block in this technology is associated with some sort of information related to data over it like source, destination information and a hash value for maintaining the integrity of data at any cost [3]. Blockchain may be called a public registry, where all signed transactions are recorded in such a blockchain. A special characteristic of blockchain is that it is like a normal chain which grows at the same time as new transactions are connected to it. The key characteristics of the blockchain technology are decentralization, durability, transparency, and audibility. The blockchain may operate in a decentralized setting, allowing multiple innovative technologies including hash algorithm, cryptographic signature, and decentralized consensus process to be incorporated. Due to its nature of transmission of data in a decentralized manner, the effectiveness of blockchain technology increases immensely and the process of transaction is extra secure [4].

Nowadays this trending technology is adopted by every field and data sector like power [5,6], online marketing [7], banking [8], governing authorities [9], medical services [10,11], education [12], agricultural development [13] and many more. Numerous problems that were considered complicated earlier s are now seen as a simple process. Many countries understand that blockchain can bring about a radical impact on the way financial transactions are performed, more so in the present and near future. The Gulf countries are also developing a different advanced technical architecture that is receptive to the transmission of modern digital data, which also has helped them makeup with others and take advantage of the new technological innovations, maximize efficiency and competitiveness, and enhance government programs.

Blockchain technology across Saudi Arabia also presents an opportunity to greatly improve the economic system in Saudi Arabia. In this direction, the Vision-2030 undertaken by the Kingdom of Saudi Arabia (KSA) is a groundbreaking nationwide quality management project guided by the fast deployment of technological interventions. The emphasis is on readjusting the economic framework which will then be focused on technological development and supported by new business models centered on emerging technologies. Saudi Arabia is also implementing ambitious steps to achieve its 2030 Vision that emphasizes on diversifying its economic system and modernizing all other sectors. The speed and efficiency of transaction processing and data accompanied by stronger fraud prevention allows this technological progress to be a desirable resource for the 2030 vision. Blockchain technology encourages the country's industrial sector and production, and significantly improves the financial sector.

Blockchain technology enables us to arrange personal information in such a manner that transactions can be checked and registered thus gaining consent from all concerned members. This technology uses the trustworthy ledger principle which keeps records of all activities. Present ledger schemes maintain records at a specific, centralized database, an Electronic Health Record 
(EHR) system, a data center or a registry operated through such an interchange of medical information. Frequently, each one of these processes is developed alongside and could produce and store information with its own compression algorithm, leading to information silos as well as interoperability problems that hinder service providers, clinicians, patients and research scientists. On the other side, a blockchain demands that every individual member, or repository, retain a duplicate of the ledger. So when a modification takes place, it has to be checked with every repository and accepted, this improves safety and decreases the probability of anyone creating some inappropriate change [14,15].

The medical sector is expanding its services and utilizing blockchain very effectively [10]. The experts cite that blockchain technology is the first choice for healthcare service providers in choosing security strategy for their services. It is also the first priority for many experts all over the world. A Report tells that average investment in this technology is going to be $\$ 5.61$ billion by 2025. As per this report, the adoption of this technology can minimize the expenditure up to $\$ 100-\$ 150$ billion annually by 2025 [16]. It has also been observed that the application and use of the blockchain technology in healthcare sector enhances the customer experience and the security of data is also maintained effectively. Kemkarl et al. tells that blockchain enabled medical record management system can control the expenditure and save up to billions of dollars. Maintaining the medical data from a digital perspective allows us to manage the post data initiation steps more effectively like its processing, in providing effective doctoral protocols, but the complex nature of healthcare system makes it difficult. Managing privacy in the advancement of healthcare data security is crucial task in the current digital scenario [17]. The healthcare industry in Saudi Arabia has already started research on blockchain to build channels for storing medical records and providing relevant information for medical study, research, and testing, in compliance with international patient privacy standards and measures. It supports the research of medical facilities, financial institutions, health insurance companies, medical equipment agencies, drug companies, as well as other personnel checking health records. The Kingdom of Saudi Arabia's 2020 budget cites an overall expenditure of SAR 1,020 billion, and estimated revenues of SAR 833 billion (Fig. 1). The government keeps on concentrating on the healthcare sectors. The healthcare sector development continues to be a top priority for the Saudi Arabian Government with the thirdlargest share of $16.4 \%$ in the 2020 budget expenditure. The health sector budget allocation comes to SAR 167 billion [18]. The following pie chart representation shows the sector-wise expenditure distribution in the 2020 budget of the Kingdom of Saudi Arabia. It clearly shows that the Government of KSA is committed to deliver good quality patient care as well as promoting the technological advancements for the healthcare and welfare of its citizens.

Saudi Arabia has already signed an agreement with IBM as well as Elm to investigate approaches for providing government and business services through the blockchain technology. The Saudi Arabian Monetary Authority (SAMA) has entered the RippleNet-associated banking blockchain network to assist domestic banks in settling of payments and making all kinds of financial transactions easier, quicker as well as secure. . In accordance with this theme, Al Rajhi Bank has made the first-ever blockchain wire transfer of Saudi Arabia from its headquarters in Riyadh to one of its branches in Jordan. In the meantime, the UAE and Saudi central banks also addressed the introduction of a blockchain-based cryptocurrency for transactions across borders [19].

Healthcare blockchain technology has the capabilities to solve a variety of issues like patient management, data protection, and interoperability. The healthcare sector produces new data each day, such as patients' reports, lab test reports, accounting, clinical studies, monitoring systems, 
as well as other records that are often stuck in various fragmented, disconnected databases. Blockchain may leverage the data stream to improve the quality of different services by streamlining the exchange of healthcare records, securing confidential data from attackers, and providing patients with a better control of their records. For example, blockchain methodology is adopted in combining the medical and pharma data records of any patient and this combined data is provided to the patient's doctor for prescribing new medication process in a more effective way. There are many other obstacles in the implementation of blockchain in healthcare sector. Given the vast and the huge economy of the KSA in Middle East Asia, implementing blockchain technology in healthcare in the country demands a highly systematic and credible mechanism. To make this challenge simple and easier for researchers, this proposed paper evaluates the use of blockchain technologies in healthcare sectors with different perspective.

\section{Expenditure by sector, SAR 1,020 billion}

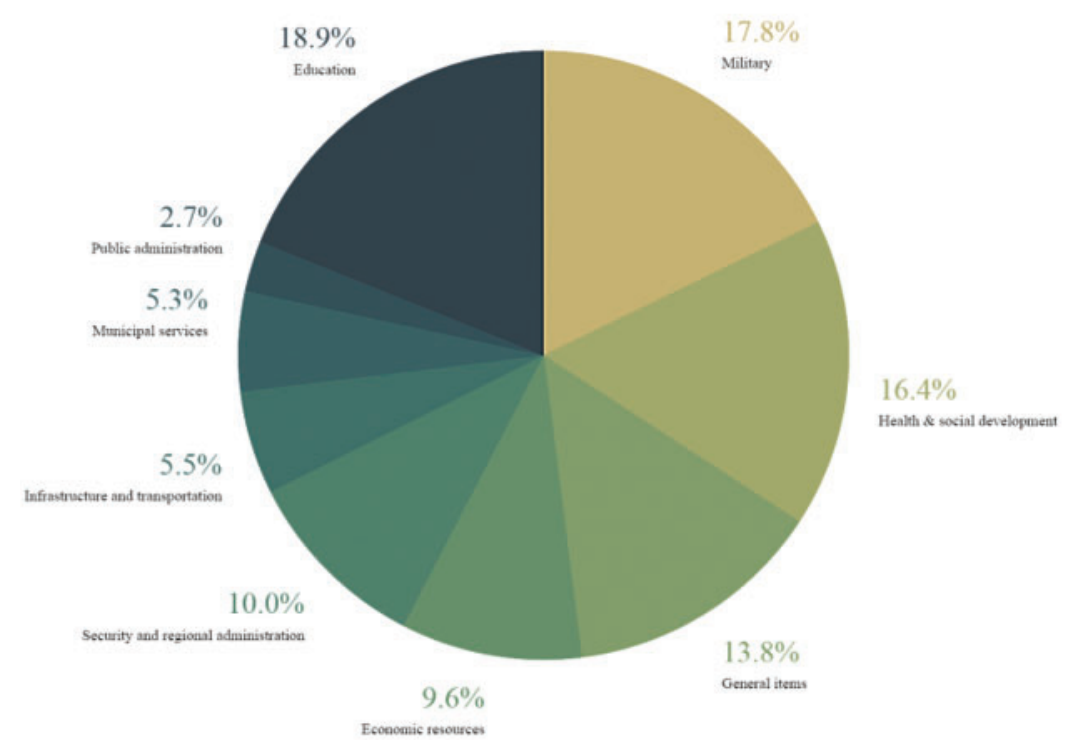

Figure 1: Kingdom of Saudi Arabia 2020 expenditure by sector

We found the MCDM approach to be the most effective one for conducting this analysis. There are several MCDM approaches and each approach has its share of pros and cons but we analysed that fuzzy-based Analytic Hierarchy Process (AHP) and Technique for Order of Preference by Similarity to Ideal Solution (TOPSIS) approaches are one of the most effective approaches amongst all the other ones [20-26].

The structure of this paper is as: Section 2 of this paper talks about the blockchain functionality over healthcare services. Section 3 of the paper discusses about the related work. Section 4 talks about methodology and sixth, seventh and eight talk about numerical analysis through different discussions, respectively. The paper concludes by discussing about the pros and cons as well as the limitations of the suggested mechanism. 


\section{Materials and Methods}

\subsection{Healthcare Blockchain Architecture}

Quality healthcare facilities that are supported by cutting edge technology is the need of the day. Blockchain is one of the most innovative technologies to have conquered the globe today. Blockchain technology has the potential to make a major difference in the healthcare environment, because it can quickly bring about practical improvements in the patient's healthcare management. Medical centers, clinics, and testing centers have to cope with emergencies regularly, and the management of records is a difficult process. Doctors and patients can use blockchain to build a comprehensive and highly effective public database processing system. The blockchain network can contain a broad range of data on several types of medication, diagnosis and tests, health and insurance records for patients and name and address for emergencies. A systematic approach is necessary to create such a large database. Moreover, routine activities such as arranging an appointment with a doctor and handling inventory levels of medications can be carried out effectively with blockchain. The platform not just presents practical performance but also a valueeffective data processing design. Blockchain technology may be of tremendous help in managing medicine and pharmaceutical repositories. Transactions among medical companies, distributors, physicians, and patients that create a personal blockchain network, as well as cryptography encryption may maintain the data safe. The following Fig. 2 shows that blockchain technology transforms every services of healthcare to make it better for all the stakeholders associated with this system. It assists healthcare service providers, clinical research scientists and patients in different healthcare fields, such as randomized controlled healthcare records, automatically generated claims, clinical research, patient portals, medical research, EHR security, and cost reduction with efficient medical supply chain management.

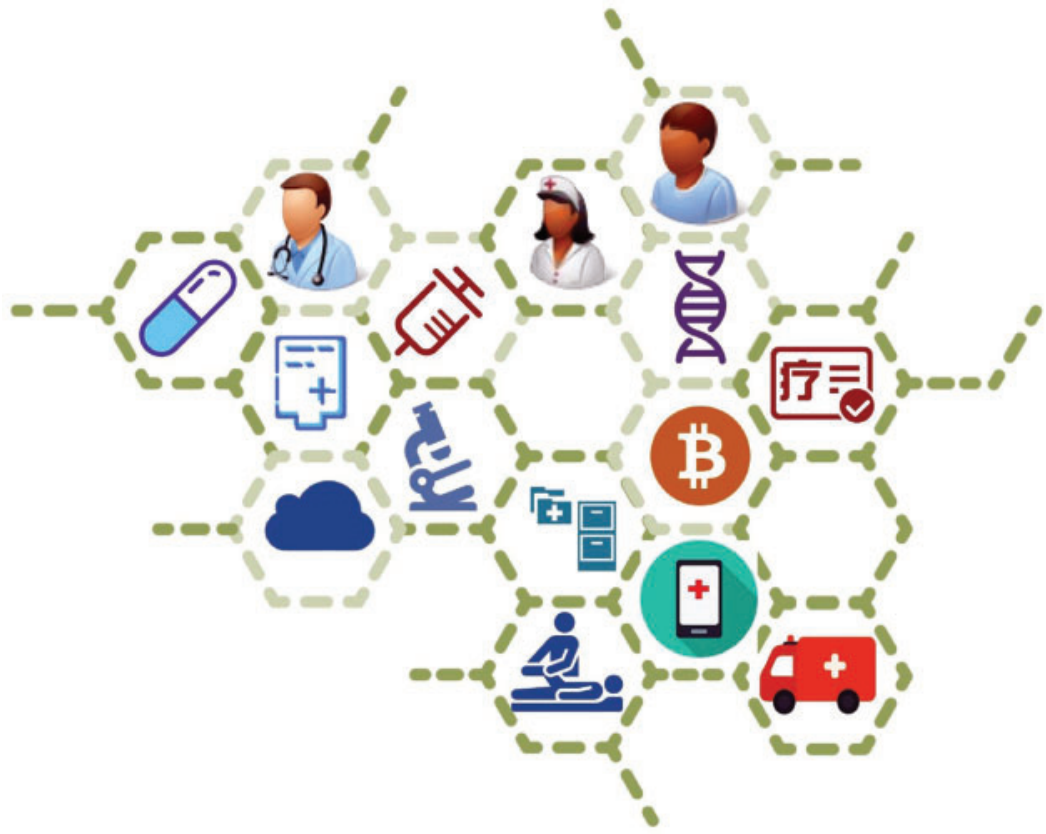

Figure 2: Blockchain technology based healthcare system 


\subsection{Blockchain Technology Based Healthcare Applications}

There are several new possibilities today for efficient management of the healthcare data, data's accessibility by the patients and distribution of the required medical information. This has been accomplished with the advancements in digital health records, cloud data infrastructure and health information privacy laws. Blockchain technology based applications in this category include mobile healthcare application; data sharing system, privacy preserving platform, financial system, PSN based healthcare system described in below headings.

\subsubsection{Mobile Healthcare Application}

The Healthcare sector has been greatly impacted by wearable technology. There are also serious data privacy and security issues, particularly in the areas of precision medicine as well as the increase of wearable devices. A mobile based healthcare application is implemented to capture health data through wearable digital devices, automatic inputs, and medical devices, as well as to synchronize cloud data for information sharing with healthcare professionals and health insurance businesses [27-33]. Patients and healthcare workers sometimes have to collect data in a safe and clear manner, transfer it over internet services, and seek assistance despite security problems. Blockchain technology is increasingly helping to resolve these kinds of issues. Blockchain is well designed for patients' record-keeping. Its responsibilities include exchanging data on hospitals, maintaining records on electronic channels, administering health insurance, and carrying out administrative duties. Today we live in a world where a database administrator can determine when a patient is going to sleep, be jogging, or doing other tasks by checking the heart rate reported by a wearable device. Through the use of a mobile application, patients can transfer their health information through a blockchain network. Medical professionals can peruse this data out and respond to the patient accordingly. Hence, it is imperative to strive for the highest protection and privacy of valuable information sent through and to a mobile-based healthcare application.

\subsubsection{EHR Management System}

Another concern is with the existing model of managing Electronic Healthcare Records (EHRs). Many healthcare institutions have shown a propensity to behave as guardians or administrators of patients' data. This results in inefficiencies and delays in the treatment of the patients. For example, treatment of a patient may be interrupted and delayed simply because the medical data received by one healthcare provider fails to reach the other in a timely way. Electronic healthcare records can be maintained in a blockchain context, using decentralized ledger, encrypted identity management as well as smart contracts. A smart contract is a computer system based protocol designed to electronically support, check or execute a contract's transaction or implementation. Smart contracts enable valid transactions to be carried out without third parties. Smart Contracts are self-executing functions programmed to initiate a command or action when connected to a trigger. An EHR focused on a Smart Contract will submit feedback on prescription medicines, issues, allergy reports, etc., to a group-wide trustworthy open-source ledger, therefore medical record improvements and rearrangements are well known and publicly available across healthcare organizations.

Blockchain technology offers a solution to address several limitations of the Electronic Healthcare Record (HER) process [21]. Wang et al. proposed a secure EHR model focused on attribute centered cryptosystem as well as blockchain technology to accomplish confidentiality, authentication and integrity of healthcare data, and facilitate perfect access control. Liang et al. [22] presented an EHR management scheme combined with the Artificial Intelligence (AI) 
and blockchain. They provided a mechanism that incorporates blockchain and artificial intelligence for safe EHR management, effective data implementation and accurate computer-aided diagnosis and treatment.

\subsubsection{Data Sharing System}

Most people today are using various types of mobile and smart wearable devices, such as smartphones, tablets, smart watches, smart bands and smart glasses, etc., with the rapid advancement of mobile-oriented computing, smart wearable technology, and wireless sensing to realize numerous medical-related applications, including remote diagnosis, healthcare supply chain management, disease monitoring, telemedicine and care giving for elderly people. Such type of healthcare services generates vast volumes of personal healthcare data, and all these data are helpful resources for scientific research and business applications of healthcare services. Appropriate exchange of patients' health data would assist all the parties involved, including app owners, patients, research scientists, organizations, as well as the entire public healthcare system. The exchange of healthcare \& medical data is a significant and critical step towards improving the quality of healthcare services and making the medical system smarter.

\subsubsection{Privacy Preserving Platform}

Transactions, as well as on-chain information transfers, are available to all peers across the entire network in many other public chains nowadays, leading to better auditability and accountability. This openness comes at a cost throughout enterprises where transmitting sensitive data is essential; presenting a dangerous risk that far exceeds the benefits. In context of healthcare, the patients are losing confidence in Electronic Healthcare Record systems as confidentiality and protection in EHR systems is being challenged by the attackers. This often brings into question the integrity and efficiency of EHR systems. Patient pseudonymity is important as confidential private healthcare data. Therefore healthcare systems must also ensure efficiency, integrity, pseudonymity, protection and privacy of patient's confidential data [23]. The transactions that protect user's privacy may draw more people who are worried regarding their privacy. Traditional privacypreserving approaches which are focused on summing up or producing noisy data are therefore not successful in healthcare applications whereby actual data from patients is needed for medical procedures. Recently many researchers have suggested new privacy preserving schemes focused on blockchain technology to resolve this issue [10].

\subsubsection{Financial System}

Blockchain enable healthcare applications to makes the transaction of medical information over a decentralized network by different parties. Information is stored in files, named as discrete records. Blockchain facilitates real-time uploading of healthcare data to platforms that link all participants to the lifecycle of a patient meeting. It provides a protected but accessible patient payment ledger through service provider, payer, and users. Financial technology (FinTech) is widely described as any technical advancement in economic services and it was the first to test and implement blockchain technology in such a traditional market. Others working in the FinTech industry are creating emerging innovations to challenge conventional financial markets [24].

\subsubsection{PSN-Based Healthcare System}

The increasing advancement of different technique of wearable technology, remote sensing and networking triggers a new paradigm of pervasive social network (PSN)-based healthcare system Latest PSN-based healthcare research is focused primarily on networks, safety and privacy, 
and implementations. Several researchers have analyzed the PSN-based e-Healthcare applications network stack. Till et al. [25] proposed the blockchain-based implementation of pervasive social network (PSN) healthcare system. PSN enables us to start sharing the medical data collected from medical sensor technology. The PSN-based medical system consists of two major security mechanisms such as the authentication protocol among medical sensors as well as wearable devices in the wireless body area network (WBAN) and the exchange of electronic healthcare record data using blockchain in the PSN region. Nodes in the PSN are accountable for creating and transmitting transactions of patient's healthcare data, i.e., nodes address and medical indicators. In contrast, the miners are accountable for the authentication of transactions and the development of new blocks.

The following Tab. 1 discussions about the domains in which this technology has been involved during its implementation in healthcare.

Table 1: Linguistic-terms and their respective TFNs

Criteria Description

Patient identity (T1) In a system where blockchain is responsible for every data transaction, there is a concept of Public Key management where the actual owner of data has the unique public key identity for managing operation over his/her data block. This type of system

Data security (T2) assures the identity and authentication requirement effectively. In these criteria, patients have the option of transferring the ownership of their data and give access to some other persons due to security and personal reasons. In this type of technological environment, every block has its own value related to source information and key distribution for encoding and decoding the block data. It is a security feature that allows blockchain type secure and manages privacy effectively.

Data monitoring (T3) Data tracking is the concept inherited from blockchain technology and effectively helps in managing the track of data. A proper ledgering system that enables the positioning situation information of data over blocks is essential for data security in healthcare.

Immutability (T4) Managing the security of healthcare information where every data is under the threat of exploitation, is a challenging and crucial task. To maintain security and the privacy, blockchain technology applies various hashing, ledgering, backup and many other small methods. All these methods and applications come under this criterion.

Consensus (T5) Blockchain methodology and its decentralized nature enable an effective countermeasure against abuse of data and exploitation attacks of healthcare information. In order to manage the EMR, every blcokchain block demands proof of work and identity before allowing them permissions.

Value (T6) This blockchain methodology rose as valuable and effective method for security management. Its value towards healthcare data security is unconditionally great and the effect is very significant. 
The pictorial representation of the Hierarchical Structure for the evaluation of healthcare blockchain technology models is given in Fig. 3.

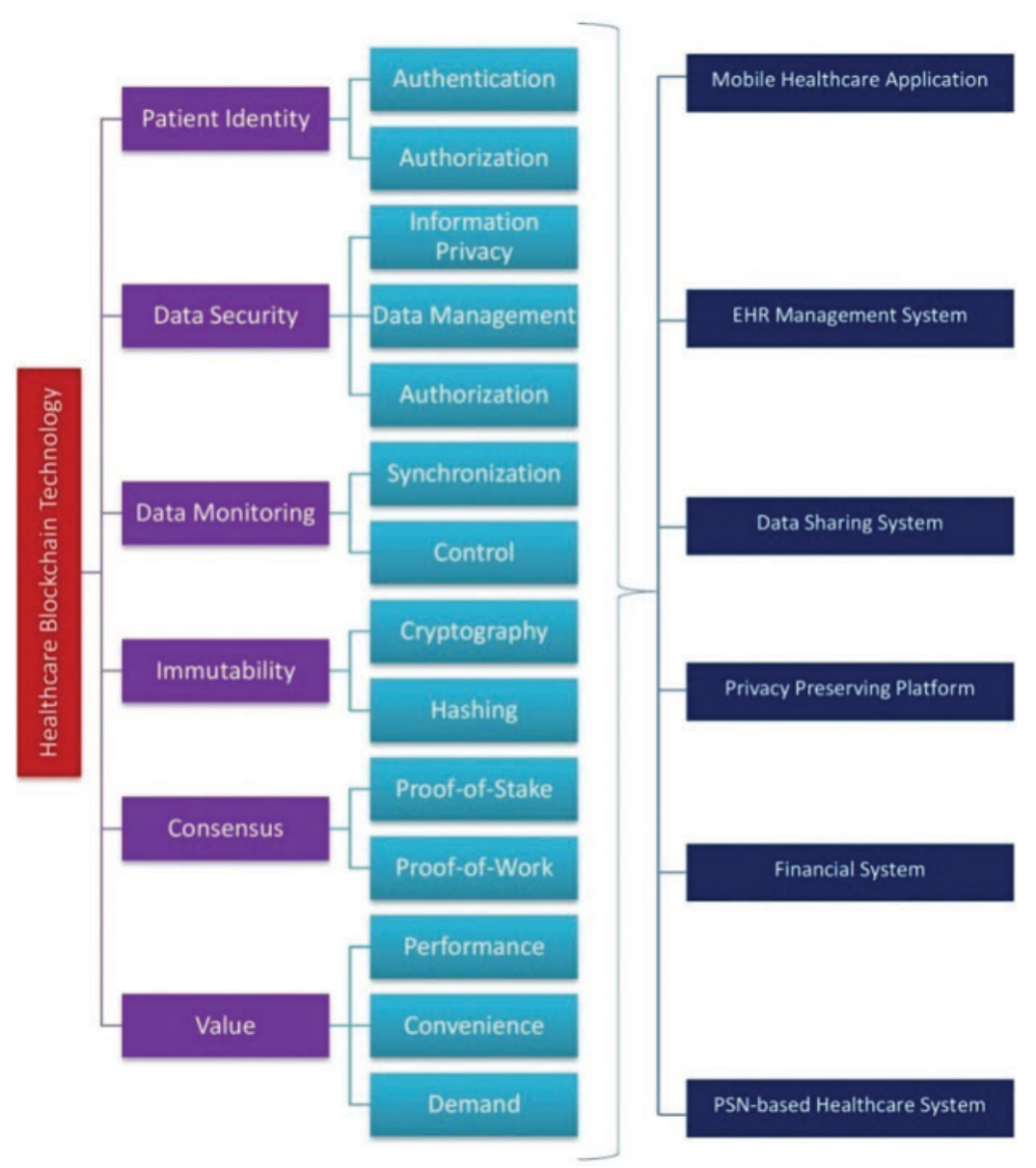

Figure 3: Hierarchy structure for evaluation of healthcare blockchain technology

\subsection{Work Done So Far}

There are several studies on fuzzy AHP-TOPSIS Multiple-criteria decision-making (MCDM) that evaluate the effect of different criteria. However, s none of them has evaluated the value and effect of blockchain in healthcare, as presented in this study.

Till et al. [25] implemented the most widely used MCDM processes, the modified TOPSIS as well as the AHP to provide a performance analysis result on the selection of machine tools. The AHP approach was used to calculate the relative weights of a group of evaluation parameters, while the modified TOPSIS approach was used to rate alternatives to competing machine tools in terms of total performance.

Rahman et al. [26] proposed a structured risk rating system for power station programs. The structure proposed may be considered as dependency between different criteria. They used the fuzzy-AHP for weight estimation. In a fuzzy-TOPSIS method, the outcomes of the fuzzy-AHP 
measurements were used to determine essential risks. They also conducted a case study of the power plant based project to illustrate the acceptability and efficiency of their proposed model.

Tavana et al. [27] proposed an integrated fuzzy system focused on the AHP group and the TOPSIS to determine the overall digital government capacity of the population from the viewpoint of Citizen Relationship Management (CiRM). They also presented the findings of a pilot study to the professionals to illustrate the uncertainties inherent in the evaluation of the digital government preparation.

Nouri et al. [28] demonstrated a complex methodology for evaluating technology and rating its suitability for a client. They proposed a hybrid model based on fuzzy AHP and fuzzy TOPSIS to accomplish the objective. They also executed a real-life case study to authenticate their proposed model.

Kuo et al. [29] constructed a supplier evaluation method system for carbon management through the combination of fuzzy AHP as well as fuzzy TOPSIS methods. They defined 13 carbon management criteria within four parameters and updated as per the viewpoint of 7 environmental division experts. They also showed that the integrated approach had a great potential to clarify the ambiguity of the speech of decision-makers with a stronger power of prejudice to determine suppliers in the carbon management process.

Ervural et al. [30] presented an advanced hybrid approach for evaluating the energy industry in Turkey leveraging strengths, weaknesses, opportunities and threats (SWOT) analysis. They used the AHP method with weighted fuzzy TOPSIS to develop and evaluate energy policy alternatives and goals in a comprehensive way. The methodology presented in their study required the use of a SWOT evaluation to classify the necessary criteria and sub-criteria. They finally showed that transforming the country into an energy market as well as an energy terminal by making appropriate use of the geo-strategic role within the regional partnership framework is the highest priority. On the other side, the least preferred priority was identified to be utilizing nuclear energy technology.

Abbaspour et al. [31] developed fuzzy AHP-TOPSIS based model to choose the best method for defining and assessing the medical errors. For this, various criteria as well as sub-criteria were decided upon by examining the available literature and relying on the opinions of domain experts.

In another study by Zarour et al. [32] three key attributes and fifteen sub-attributes were selected at Levels 1 and 2, accordingly, with ten separate program alternatives. In addition, this analysis used a fuzzy AHP-TOPSIS symmetrical decision-making methodology to evaluate blockchain security in relation to strategies.

\subsection{Methodology Followed}

The adopted research methodology provides a systematic, step-wise procedure to carry out the experiment on healthcare information systems. For this study, fuzzy based AHP-TOPSIS has been implemented. AHP-TOPSIS is a hybrid integrated approach that comes under the umbrella of MCDM problem solving domain [32]. In this work, AHP-TOPSIS is practiced under the fuzzy logic environment that makes it efficient and effective for producing more accurate results. Fuzzy logic, as an advanced form of classical logic, has acquired utmost significance in those areas where solution of the problem may take any value from absolute true to absolute false. It can be absolutely true, partially true, absolutely false, or partially false. It comes with the ability to handle uncertainty of the information [1]. 
Analytical hierarchical process, which is an MCDM problem solving technique, is the most suitable technique for addressing the problems that can produce multiple solutions. It analyzes the problem in a hierarchical fashion. AHP provides accurate calculations in case of the attributes' subjective and objective values in comparison to other MCDM approaches [32]. Furthermore, it measures the attributes' strength and consistency as determined by the decisions of the experts. TOPSIS is best known for alternative ranking in the MCDM problem domain. Its working concept is to find the best alternative among the set of competing alternatives and rank all the available alternatives according to their performance scores. In this study, fuzzy based AHP is first applied to determine the weights of criteria (factors/attributes) and then fuzzy based TOPSIS is practiced to produce the ranking of alternatives. Fig. 4 provides the step-wise working procedure of this work. In the following sub-section, numerical formulae are provided for reference.

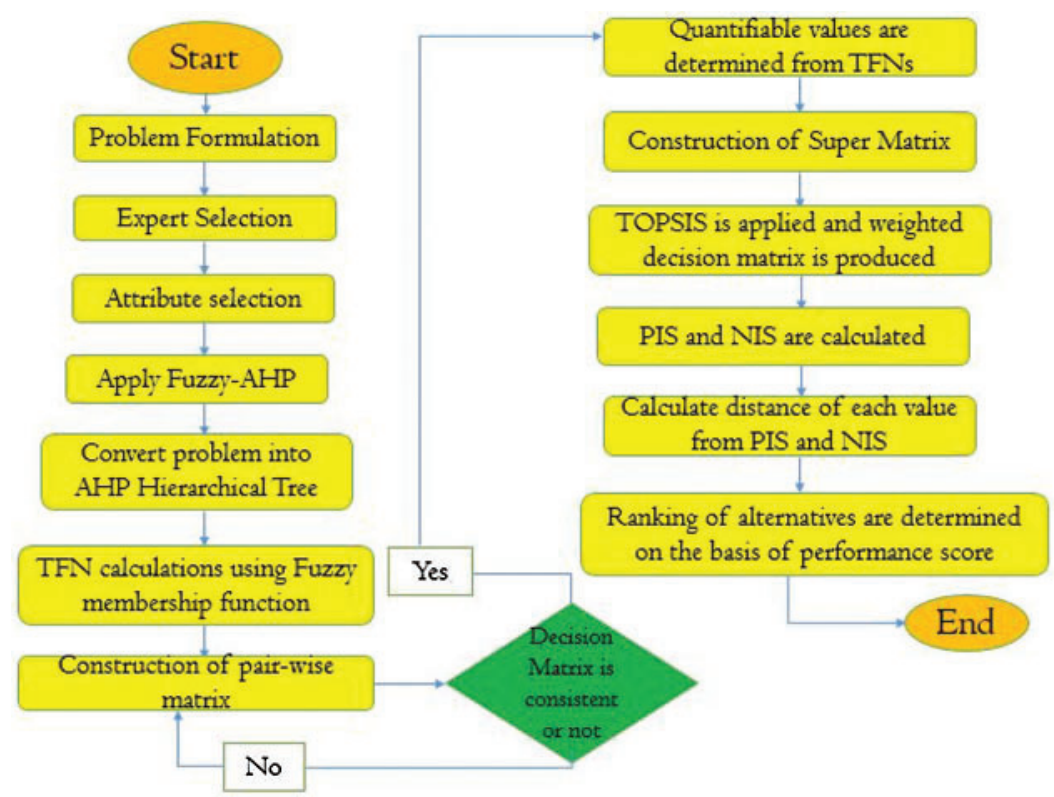

Figure 4: Working diagram of fuzzy based AHP-TOPSIS

Step_1: Triangular Fuzzy Number $(\mathrm{TFN})$ is structurally a triplet (f1, f2, f3) where f1 < f2 $<\mathrm{f} 3$ and $\mathrm{f} 1$ symbolize lower value, $\mathrm{f} 2$ middle one and $<\mathrm{f} 3$ symbolizes higher value. Membership function of the fuzzy number $\sim \mathrm{T}$ is demonstrated with the help of Eqs. (1)-(2) and the number is known as TFN. Fig. 5 depicts the structure of a TFN.

$\mu_{\mathrm{T}}(\mathrm{x})=\mathrm{F} \rightarrow[0,1]$

$\mu_{\mathrm{T}}(\mathrm{x})= \begin{cases}\frac{\mathrm{f} 1-\mathrm{f} 2}{\mathrm{f} 2-\mathrm{f} 1}, & \mathrm{f} 1 \leq \mathrm{x} \leq \mathrm{f} 2 \\ \frac{\mathrm{f} 3-\mathrm{x}}{\mathrm{f} 3-\mathrm{f} 2}, & \mathrm{f} 2 \leq \mathrm{x} \leq \mathrm{f} 3 \\ 0, & \mathrm{x}>f 3 \quad \text { Otherwise }\end{cases}$ 
To assign value to each attribute, first, the well-known linguistic terms and then their respective numeric values, the experts used the "Saaty Scale" (Tab. 2).

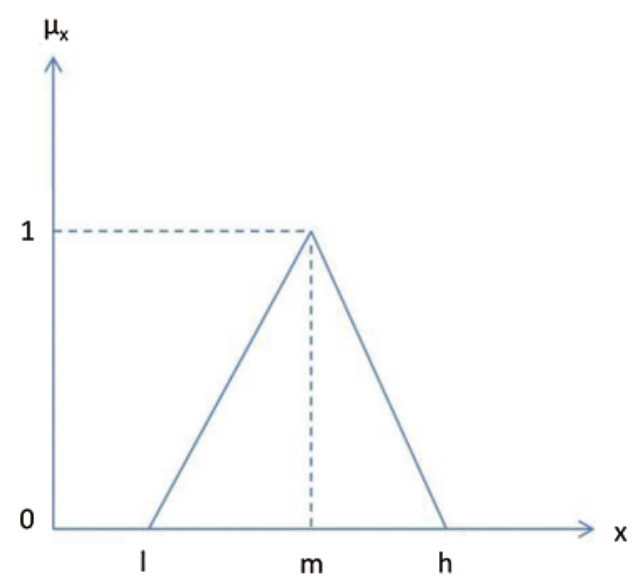

Figure 5: Structure of a TFN

Table 2: Linguistic-terms and their respective TFNs

\begin{tabular}{lll}
\hline Saaty scale definition & Fuzzy triangular scale & \\
\hline 1 & Equally important & $(1,1,1)$ \\
3 & Weakly important & $(2,3,4)$ \\
5 & Fairly important & $(4,5,6)$ \\
7 & Strongly important & $(6,7,8)$ \\
9 & Absolutely important & $(9,9,9)$ \\
2 & Intermittent values between & $(1,2,3)$ \\
4 & two adjacent scales & $(3,4,5)$ \\
6 & & $(5,6,7)$ \\
8 & & $(7,8,9)$ \\
\hline
\end{tabular}

After that, fuzzy conversion is performed on these numeric values. To convert numeric values into TFNs, Eqs. (3)-(6) are applied and symbolized as (flij, f2ij, f3ij) where, flij presents low value, f2ij presents middle one and f3ij presents upper value. Further, TFN [ $\eta \mathrm{ij}]$ is defined as:

$\eta_{\mathrm{ij}}=\left(\mathrm{f} 1_{\mathrm{ij}}, \mathrm{f} 2_{\mathrm{ij}}, \mathrm{f} 3_{\mathrm{ij}}\right)$

where, $\quad \mathrm{f} 1_{\mathrm{ij}} \leq \mathrm{f} 2_{\mathrm{ij}} \leq \mathrm{f} 3_{\mathrm{ij}}$

$\mathrm{f} 1_{\mathrm{ij}}=\min \left(\mathrm{J}_{\mathrm{ijd}}\right)$

$\mathrm{f} 2_{\mathrm{ij}}=\left(\mathrm{J}_{\mathrm{ij} 1}, \mathrm{~J}_{\mathrm{ij} 2}, \mathrm{~J}_{\mathrm{ij} 3}\right)^{\frac{1}{\mathrm{x}}}$

and $\mathrm{f} 3_{\mathrm{ij}}=\max \left(\mathrm{J}_{\mathrm{ijd}}\right)$

The relative importance of values among two attributes is denoted by Jijk with the help of experts' opinions and the equations given above. The attribute pairs are judged and denoted by 
$\mathrm{i}$ and j. Further, the operations on the two TFNs are performed with the help of Eqs. (7)-(9). Suppose, $\mathrm{T} 1$ and $\mathrm{T} 2$ are two TFNs, $\mathrm{T} 1=(\mathrm{f} 11, \mathrm{f} 21, \mathrm{f} 31)$ and $\mathrm{T} 2=(\mathrm{f} 12, \mathrm{f} 22, \mathrm{f} 32)$. Then, the operational rules on them would be:

$$
\begin{aligned}
& \left(\mathrm{f} 1_{1}, \mathrm{f} 2_{1}, \mathrm{f} 3_{1}\right)+\left(f 1_{2}, f 2_{2}, f 3_{2}\right)=\left(f 1_{1}+f 1_{2}, f 2_{1}+f 2_{2}, f 3_{1}+f 3_{2}\right) \\
& \left(\mathrm{f} 1_{1}, \mathrm{f} 2_{1}, \mathrm{f} 3_{1}\right) \times\left(\mathrm{f} 1_{2}, \mathrm{f} 2_{2}, \mathrm{f} 3_{2}\right)=\left(\mathrm{f} 1_{1} * \mathrm{f} 1_{2}, \mathrm{f} 2_{1} * \mathrm{f} 2_{2}, \mathrm{f} 3_{1} * \mathrm{f} 3_{2}\right) \\
& \left(\mathrm{f} 1_{1}, \mathrm{f} 2_{1}, \mathrm{f} 3_{1}\right)^{-1}=\left(\frac{1}{\mathrm{f} 3_{1}}, \frac{1}{\mathrm{f} 2_{1}}, \frac{1}{\mathrm{f} 1_{1}}\right)
\end{aligned}
$$

Step_2: Experts' responses are to be used to establish pair-wise comparison matrix and by applying Eqs. (10)-(11), Consistency Index (CI) can be determined as follows:

$\mathrm{CI}=\left(\gamma_{\max }-\mathrm{q}\right) /(\mathrm{q}-1)$

where, CI: Consistency Index and q: number of compared elements.

Also, Consistency Ratio (CR) can be calculated by using a random index:

$\mathrm{CR}=\mathrm{CI} / \mathrm{RI}$

Generated matrix is reasonably called consistent if $\mathrm{CR}<0.1$. Where, random index is specified by RI and is taken from Arsene et al. [16].

Step_3: After the completion of step_2 of the work, result is obtained in the form of a reasonably consistent matrix. Then by applying defuzzification (alpha-cut) method taken from TFN values would be converted to quantifiable values. Defuzzification is to be determined through Eqs. (12)-(14):

$\mu_{\alpha, \beta}\left(\eta_{\mathrm{ij}}\right)=\left[\beta . \eta \alpha\left(\mathrm{f1}_{\mathrm{ij}}\right)+(1-\beta) . \eta \alpha\left(\mathrm{f} 3_{\mathrm{ij}}\right)\right]$

where, $0 \leq \alpha \leq 1$ and $0 \leq \beta \leq 1$

Such that,

$\eta \alpha\left(\mathrm{f} 1_{\mathrm{ij}}\right)=\left(\mathrm{f} 2_{\mathrm{ij}}-\mathrm{f} 1_{\mathrm{ij}}\right) \cdot \alpha+\mathrm{f} 1_{\mathrm{ij}}$

$\eta \alpha\left(\mathrm{f} 3_{\mathrm{ij}}\right)=\mathrm{f} 3_{\mathrm{ij}}-\left(\mathrm{f} 3_{\mathrm{ij}}-\mathrm{f} 2_{\mathrm{ij}}\right) \cdot \alpha$

The values of $\alpha$ and $\beta$ lie between 0 and 1; as used in the above equations.

Step_4: In this step, the process of paired comparisons between groups including goal, attributes, sub-attributes, and alternatives in the form of priority vector is done. These comparisons help in the formation of the super-matrix.

Step_5: In TOPSIS, determination of performance score of every alternative over each normalized factor is calculated by the Eq. (15) that is as:

$X_{i j}=\frac{x_{i j}}{\sqrt{\sum_{i=1}^{m} x_{i j}^{2}}}$

where, $\mathrm{i}=1$ to $\mathrm{m}$; and $\mathrm{j}=1$ to $\mathrm{n}$.

With the help of Eq. (16), calculations are performed to construct Normalized WeightedDecision Matrix.

$\mathrm{D}_{\mathrm{ij}}=\mathrm{w}_{\mathrm{i}} \mathrm{X}_{\mathrm{ij}}$ 
where, $\mathrm{i}=1$ to $\mathrm{m}$ and $\mathrm{j}=1$ to $\mathrm{n}$.

To collect the experts' responses, fuzzy based TOPSIS technique also uses the concept of TFN and linguistic-terms. The following Tab. 3 provides sufficient information about the semantic word set classification [4].

Table 3: Linguistic scales for the rating

\begin{tabular}{ll}
\hline Linguistic variables & Corresponding TFN \\
\hline Very poor (VP) & $(0,1,3)$ \\
Poor (P) & $(1,3,5)$ \\
Fair (F) & $(3,5,7)$ \\
Good (G) & $(5,7,9)$ \\
Very good (VG) & $(7,9,10)$ \\
\hline
\end{tabular}

Step_6: In this step, the +ve ideal solution (PIS) matrix and -ve ideal solution (NIS) matrix are generated with the help of Eq. (17) given below.

$\mathrm{V}^{+}=\mathrm{p}_{1}^{+}, \mathrm{p}_{2}^{+}, \mathrm{p}_{3}^{+}, \ldots, \mathrm{p}_{\mathrm{n}}^{+}$

$\mathrm{V}^{-}=\mathrm{p}_{1}^{-}, \mathrm{p}_{2}^{-}, \mathrm{p}_{3}^{-}, \ldots, \mathrm{p}_{\mathrm{n}}^{-}$

where, $p_{j}^{+}$is Max pij, if $\mathrm{j}$ is an advantage factor, and Max pij, if $\mathrm{j}$ is a cost factor;

$p_{j}^{-}$is Min pij if $\mathrm{j}$ is an advantage factor, and Min pij, if $\mathrm{j}$ is a cost factor.

Step_7: In this step with respect to PIS and NIS, distance of each option value is identified with the help of Eqs. (18)-(19).

$s_{i}^{+}=\sqrt{\sum_{j=1}^{m}\left(p_{i}^{+}-p_{i j}\right)^{2}} ; \quad i=1$ to $m$

NIS:

$s_{i}^{-}=\sqrt{\sum_{j=1}^{m}\left(p_{i j}-p_{i}^{-}\right)^{2}} ; \quad$ where, $i=1$ to $m$

Where, the distance to PIS for the option $\mathrm{i}$ is defined by $\mathrm{s}_{\mathrm{j}}^{+}$and the distance to NIS is defined by $\mathrm{s}_{\mathrm{i}}^{-}$.

For each alternative (Pi), the preference value is calculated with the Eq. (20).

$\mathrm{P}=\frac{\mathrm{s}_{\mathrm{i}}^{-}}{\mathrm{s}_{\mathrm{i}}^{-}-\mathrm{s}_{\mathrm{i}}^{+}}$

where, $\mathrm{i}=1,2,3 \ldots, \mathrm{m}$ 
The above discussed systematic step-wise methodology will be adopted in this work to carry out a case study on healthcare web applications for security assessment. In the next section of this work, we have provided numerical calculations along with the results of this study.

\section{Data Analysis and Results}

Estimating the Impact of blockchain technology is objectively a qualitative measurement. The importance of performance attributes plays a major role throughout the blockchain development process in creating stable as well as efficiently functional business applications. As a research study, this analysis corresponds to the use of fuzzy AHP-TOPSIS to a method for the blockchain technology impact evaluation for electronic healthcare records in the perspective of the Kingdom of Saudi Arabia. For assessing security evaluation from a security strategies perspective, three Level1 parameters, namely Patient Identity, Data Security, Data Monitoring, Immutability, Consensus and Value, are defined respectively as T1-T6.

Regarding the blockchain technology impact evaluation for EHRs from the perspective of the Kingdom of Saudi Arabia at its second level, the classification is as: patient identity is authentication and authorization, and is represented as T11, T12, respectively. The sub level of second criteria is displayed in computational analysis is represented from T21-T23. Moreover next main criteria have two sub levels in Fig. 3 and they are displayed as T31 and T32. Further all the three remaining main criteria's has T41, T42, T51, T52, T61-T63 sub criteria's respectively that are discussed in the Fig. 3. To compute the significant effect of blockchain in healthcare security and its management is performed by adopted methodology of fuzzy AHP-TOPSIS and to perform the computational process, the examiners adopt Eqs. (1)-(20). The evaluated numerical outcome is displayed in Tabs. 4-21.

To perform the evaluation process, the methodology adopts Saaty's rule and examiners transform the numerical values into linguistic value, with the help of Figs. 3, 4 and Eqs. (1)-(2). After a successful transaction between the values, the methodology demands to change the obtained linguistic terms into triangular fuzzy numbers. By using the TFNs, the examiners prepare the matrixes for evaluation, with the help of Tab. 2, Eqs. (3)-(11) and Step 3 of the methodology. Further, after implementing the adopted methodology, the authors find the following matrixes for level one and second criteria's that are shown in Tabs. 4-10. Now, after identifying these matrixes through methodology, the examiners defuzzify the matrix for performing alpha-cut method. The calculated results are shown in Tabs. 11-17. The results have been obtained with the help of Eqs. (12)-(14) and Step 4 of the methodology. Further, Tab. 18 shows the global weights of the criteria at levels 1 and 2 .

Moreover, after identifying the weights and ranks of every criteria and sub criteria, the Authors validate and test their obtained results through a simulation methodology named TOPSIS, as discussed in the previous section. This methodology performs a computational simulation of priority list obtained by fuzzy-AHP methodology and tests whether the results are effective or not. For this research work, the TOPSIS methodology is implemented on alternatives taken by the authors as hospitals. The obtained priority list is tested on them for gauging the efficacy of the results in a simulation manner.

To validate and test the obtained results, we used Tab. 3 and Eqs. (15)-(20) for assessing the TOPSIS results. Further, with the help of Eqs. (15)-(20), subjective cognition results of evaluators in linguistic terms, normalized fuzzy-decision matrix and weighted normalized fuzzy-decision 
matrix are calculated and the outcomes are shown in Tabs. 19 and 20, respectively. Finally, Tab. 21 and Fig. 6 show the closeness coefficients of different alternatives.

Table 4: Aggregated fuzzy pair wise comparison matrix at level 1

\begin{tabular}{|c|c|c|c|c|c|c|}
\hline & $\mathrm{T} 1$ & $\mathrm{~T} 2$ & T3 & $\mathrm{T} 4$ & $\mathrm{~T} 5$ & T6 \\
\hline $\mathrm{T} 1$ & $\begin{array}{l}1.000000, \\
1.000000, \\
1.000000\end{array}$ & $\begin{array}{l}1.756000 \\
2.350000 \\
3.034000\end{array}$ & $\begin{array}{l}1.483000, \\
1.958000, \\
2.529000\end{array}$ & $\begin{array}{l}1.128000 \\
1.554000 \\
1.988000\end{array}$ & $\begin{array}{l}0.221500 \\
0.287100 \\
0.415200\end{array}$ & $\begin{array}{l}0.314600, \\
0.461000, \\
0.870500\end{array}$ \\
\hline $\mathrm{T} 2$ & - & $\begin{array}{l}1.000000, \\
1.000000, \\
1.000000\end{array}$ & $\begin{array}{l}0.570000 \\
0.786000 \\
1.156000\end{array}$ & $\begin{array}{l}0.570000 \\
0.720000 \\
0.970000\end{array}$ & $\begin{array}{l}0.267090 \\
0.352100 \\
0.517060\end{array}$ & $\begin{array}{l}0.166300, \\
0.196900, \\
0.253100\end{array}$ \\
\hline $\mathrm{T} 3$ & - & - & $\begin{array}{l}1.000000, \\
1.000000, \\
1.000000\end{array}$ & $\begin{array}{l}0.627000 \\
0.812000 \\
1.072000\end{array}$ & $\begin{array}{l}0.300900 \\
0.435020 \\
0.802070\end{array}$ & $\begin{array}{l}0.802700, \\
0.870500, \\
1.000000\end{array}$ \\
\hline $\mathrm{T} 4$ & - & - & - & $\begin{array}{l}1.000000 \text {, } \\
1.000000, \\
1.000000\end{array}$ & $\begin{array}{l}0.538060 \\
0.914300 \\
1.583600\end{array}$ & $\begin{array}{l}0.608300, \\
1.059200, \\
1.682090\end{array}$ \\
\hline T5 & - & - & - & - & $\begin{array}{l}1.000000 \text {, } \\
1.000000, \\
1.000000\end{array}$ & $\begin{array}{l}0.415020, \\
0.637020, \\
1.179010\end{array}$ \\
\hline T6 & - & - & - & - & - & $\begin{array}{l}1.000000, \\
1.000000, \\
1.000000\end{array}$ \\
\hline
\end{tabular}

Table 5: Aggregated fuzzify pair wise comparison matrix for patient identity at level 2

\begin{tabular}{lll}
\hline & T11 & T12 \\
\hline T11 & $1.000000,1.000000,1.000000$ & $0.31270,0.43950,0.62520$ \\
T12 & - & $1.000000,1.000000,1.000000$
\end{tabular}

Table 6: Aggregated fuzzy pair wise comparison matrix for data security at level 2

\begin{tabular}{llll}
\hline & T21 & T22 & T23 \\
\hline T21 & $1.000000,1.000000,1.000000$ & $2.04510,3.16990,4.23300$ & $0.26650,0.36570,0.59110$ \\
T22 & - & $1.000000,1.000000,1.000000$ & $0.36670,0.52510,0.96590$ \\
T23 - & - & $1.000000,1.000000,1.000000$ \\
\hline
\end{tabular}

Six organizational alternatives' defined output is as follows: the A1, A4, A2, A5, A3 and A6. According to this research study's evaluation, amongst the six sustainable alternatives, the A1 offers the best security framework in the context of blockchain technology. 
Table 7: Aggregated fuzzy pair wise comparison matrix for data monitoring at level 2

\begin{tabular}{lll}
\hline & T31 & T32 \\
\hline T31 & $1.000000,1.000000,1.000000$ & $0.87330,0.90120,0.94650$ \\
T32 & - & $1.000000,1.000000,1.000000$ \\
\hline
\end{tabular}

Table 8: Aggregated fuzzy pair wise comparison matrix for immutability at level 2

\begin{tabular}{lll}
\hline & T41 & T42 \\
\hline T41 & $1.000000,1.000000,1.000000$ & $0.32300,0.44800,0.60510$ \\
T42 & - & $1.000000,1.000000,1.000000$
\end{tabular}

Table 9: Aggregated fuzzy pair wise comparison matrix for consensus at level 2

\begin{tabular}{lll}
\hline & T51 & T52 \\
\hline T51 & $1.000000,1.000000,1.000000$ & $0.22610,0.29280,0.41660$ \\
T52 & - & $1.000000,1.000000,1.000000$ \\
\hline
\end{tabular}

Table 10: Aggregated fuzzy pair wise comparison matrix for value at level 2

\begin{tabular}{llll}
\hline & T61 & T62 & T63 \\
\hline T61 $1.000000,1.000000,1.000000$ & $0.25800,0.33806,0.50550$ & $0.69060,1.00590,1.51170$ \\
T62 - & $1.000000,1.000000,1.000000$ & $0.36004,0.52200,0.80740$ \\
T63 - & - & $1.000000,1.000000,1.000000$ \\
\hline
\end{tabular}

Table 11: Local weight of attributes at level 1

\begin{tabular}{llllllll}
\hline & T1 & T2 & T3 & T4 & T5 & T6 & Weights \\
\hline T1 & 1.00000 & 2.37230 & 1.98190 & 1.55640 & 0.30270 & 0.52680 & 0.160320 \\
T2 & 0.42150 & 1.00000 & 0.82430 & 0.74470 & 0.37240 & 0.20330 & 0.078170 \\
T3 & 0.50460 & 1.21320 & 1.00000 & 0.83090 & 0.49350 & 0.85200 & 0.117430 \\
T4 & 0.64250 & 1.34280 & 1.20350 & 1.00000 & 0.96360 & 1.10240 & 0.157780 \\
T5 & 1.89820 & 4.91880 & 1.17370 & 0.90710 & 1.00000 & 0.71720 & 0.243680 \\
T6 & 0.85540 & 1.53970 & 0.54450 & 0.74010 & 1.39430 & 1.00000 & 0.242630 \\
CR $=0.06410400$ & & & & & & \\
\hline
\end{tabular}

\subsection{Sensitivity Analysis}

Sensitivity analysis as a technique or tool has a significant role in validating a research analysis. It is practiced for finding the impact or effect of independent variable on dependent variable when changes are made in the values of the independent variables. The resulted weights generated by fuzzy based AHP-TOPSIS have been considered as variables. The selected attribute's 
weight is changed in every experiment, while the weights of the other attributes remain constant. A descriptive representation of sensitivity analysis is shown in Tab. 22.

Table 12: Local weight of attributes for patient identity at level 2

\begin{tabular}{llll}
\hline & T11 & T12 & Weights \\
\hline T11 & 1.00000 & 0.45420 & 0.312340 \\
T12 & 2.20170 & 1.00000 & 0.687660 \\
CR $=0.000000$ & & \\
\hline
\end{tabular}

Table 13: Local weight of attributes for data security at level 2

\begin{tabular}{lllll}
\hline & T21 & T22 & T23 & Weights \\
\hline T21 & 1.00000 & 0.15450 & 0.39730 & 0.329860 \\
T22 & 0.31700 & 1.00000 & 0.59570 & 0.175530 \\
T23 & 2.51690 & 1.67870 & 1.00000 & 0.494610 \\
CR $=0.03649300$ & & & \\
\hline
\end{tabular}

Table 14: Local weight of attributes for data monitoring at level 2

\begin{tabular}{llll}
\hline & T31 & T32 & Weights \\
\hline T31 & 1.00000 & 0.90560 & 0.475230 \\
T32 & 1.10420 & 1.00000 & 0.524770 \\
CR $=0.000000$ & & \\
\hline
\end{tabular}

Table 15: Local weight of attributes for immutability at level 2

\begin{tabular}{llll}
\hline & T41 & T42 & Weights \\
\hline T41 & 1.000000 & 0.456100 & 0.313230 \\
T42 & 2.192500 & 1.000000 & 0.686770 \\
CR $=0.000000$ & & \\
\hline
\end{tabular}

Table 16: Local weight of attributes for consensus at level 2

\begin{tabular}{llll}
\hline & T51 & T52 & Weights \\
\hline T51 & 1.00000 & 0.30710 & 0.234950 \\
T52 & 3.25630 & 1.00000 & 0.765050 \\
CR $=0.000000$ & & \\
\hline
\end{tabular}


Table 17: Local weight of attributes for value at level 2

\begin{tabular}{lllll}
\hline & T61 & T62 & T63 & Weights \\
\hline T61 & 1.00000 & 0.36020 & 1.05360 & 0.235460 \\
T62 & 2.77620 & 1.00000 & 0.55300 & 0.375170 \\
T63 & 0.94910 & 1.80830 & 1.00000 & 0.389370 \\
CR $=0.07266200$ & & & \\
\hline
\end{tabular}

Table 18: Global weights through the hierarchy

\begin{tabular}{|c|c|c|c|c|c|}
\hline $\begin{array}{l}\text { First level } \\
\text { attributes }\end{array}$ & Local weights & $\begin{array}{l}\text { Second level } \\
\text { attributes }\end{array}$ & Local weights & Global weights & Ranks \\
\hline \multirow[t]{2}{*}{$\mathrm{T} 1$} & 0.160320 & $\mathrm{~T} 11$ & 0.312340 & 0.0500743 & 10 \\
\hline & & $\mathrm{T} 12$ & 0.687660 & 0.1102457 & 2 \\
\hline \multirow[t]{3}{*}{$\mathrm{T} 2$} & 0.078170 & $\mathrm{~T} 21$ & 0.329860 & 0.0257852 & 13 \\
\hline & & $\mathrm{T} 22$ & 0.175530 & 0.0137212 & 14 \\
\hline & & $\mathrm{T} 23$ & 0.494610 & 0.0386637 & 12 \\
\hline \multirow[t]{2}{*}{$\mathrm{T} 3$} & 0.117430 & T31 & 0.475230 & 0.0558063 & 9 \\
\hline & & T32 & 0.524770 & 0.0616237 & 6 \\
\hline \multirow[t]{2}{*}{$\mathrm{T} 4$} & 0.157780 & T41 & 0.313230 & 0.0494214 & 11 \\
\hline & & T42 & 0.686770 & 0.1083586 & 3 \\
\hline \multirow[t]{2}{*}{ T5 } & 0.243680 & T51 & 0.234950 & 0.0572526 & 7 \\
\hline & & T52 & 0.765050 & 0.1864274 & 1 \\
\hline \multirow[t]{3}{*}{ T6 } & 0.242630 & T61 & 0.235460 & 0.0571297 & 8 \\
\hline & & T62 & 0.375170 & 0.0910275 & 5 \\
\hline & & T63 & 0.389370 & 0.0944728 & 4 \\
\hline
\end{tabular}

For performing the sensitivity analysis for validating and analyzing the usefulness of the obtained result, the authors evaluated the coefficient closeness value for every alternative in a different resource environment that is called experiment. The authors increased or decreased the value of an alternative in a specific experiment; the remaining alternatives have the same values which were obtained in the previous results. This type of fluctuation in source data gives an unbalanced situation to the computational approach and it provides the uncertainty level of the results through the experiments. This experiment provides the results' effectiveness.

Moreover, during the sensitivity analysis for this proposed article, the authors found that the results are very convincing and do not provide extra uncertainty.

\subsection{Comparison of the Results}

Problem domains where we are not able to decide whether the solution of the specified problem is completely true or completely false come under the ambit of MCDM problems. Efforts to derive solutions for these problems without considering their imprecision will produce inefficient results. Fuzzy-logic has a significant importance in finding efficient and effective results for these problems. To apply this ideology and compare the effectiveness of adopted methodology, the authors performed a comparison analysis of results through various other MCDM approaches and its result is discussed in Tab. 23. 
Table 19: Subjective cognition results of evaluators in linguistic terms

\begin{tabular}{|c|c|c|c|c|c|c|}
\hline & $\mathrm{A}_{1}$ & $\mathrm{~A}_{2}$ & $\mathrm{~A}_{3}$ & $\mathrm{~A}_{4}$ & $\mathrm{~A}_{5}$ & $\mathrm{~A}_{6}$ \\
\hline T11 & $\begin{array}{l}4.450000 \\
6.450000 \\
8.180000\end{array}$ & $\begin{array}{l}2.360000 \\
4.270000 \\
6.270000\end{array}$ & $\begin{array}{l}1.200000 \\
3.000000 \\
5.000000\end{array}$ & $\begin{array}{l}1.360000 \\
3.360000 \\
5.360000\end{array}$ & $\begin{array}{l}3.730000 \\
5.550000 \\
7.270000\end{array}$ & $\begin{array}{l}2.820000, \\
4.820000, \\
6.730000\end{array}$ \\
\hline T12 & $\begin{array}{l}4.450000, \\
6.450000, \\
8.270000\end{array}$ & $\begin{array}{l}4.820000 \\
6.820000 \\
8.550000\end{array}$ & $\begin{array}{l}1.090000, \\
2.820000, \\
4.820000\end{array}$ & $\begin{array}{l}0.820000 \\
2.640000 \\
4.640000\end{array}$ & $\begin{array}{l}2.360000, \\
4.270000, \\
6.270000\end{array}$ & $\begin{array}{l}1.200000, \\
3.000000, \\
5.000000\end{array}$ \\
\hline $\mathrm{T} 21$ & $\begin{array}{l}5.730000 \\
7.730000 \\
9.270000\end{array}$ & $\begin{array}{l}5.550000 \\
7.500005 \\
9.270000\end{array}$ & $\begin{array}{l}1.820000 \\
3.730000 \\
5.730000\end{array}$ & $\begin{array}{l}1.640000 \\
3.550000 \\
5.550000\end{array}$ & $\begin{array}{l}4.820000 \\
6.820000 \\
8.550000\end{array}$ & $\begin{array}{l}1.090000, \\
2.820000, \\
4.820000\end{array}$ \\
\hline T22 & $\begin{array}{l}5.180000 \\
7.180000 \\
8.820000\end{array}$ & $\begin{array}{l}4.270000 \\
6.270000 \\
8.180000\end{array}$ & $\begin{array}{l}1.730000 \\
3.550000 \\
5.550000\end{array}$ & $\begin{array}{l}1.180000 \\
3.000000 \\
5.000000\end{array}$ & $\begin{array}{l}5.550000 \\
7.500005 \\
9.270000\end{array}$ & $\begin{array}{l}1.820000, \\
3.730000, \\
5.730000\end{array}$ \\
\hline T23 & $\begin{array}{l}3.180000 \text {, } \\
5.180000 \text {, } \\
7.180000\end{array}$ & $\begin{array}{l}5.730000 \\
7.730000 \\
9.270000\end{array}$ & $\begin{array}{l}1.640000, \\
3.550000, \\
5.550000\end{array}$ & $\begin{array}{l}1.640000 \\
3.550000 \\
5.550000\end{array}$ & $\begin{array}{l}4.820000, \\
6.820000, \\
8.550000\end{array}$ & $\begin{array}{l}1.090000 \text {, } \\
2.820000 \text {, } \\
4.820000\end{array}$ \\
\hline $\mathrm{T} 31$ & $\begin{array}{l}2.820000 \\
4.820000 \\
6.820000\end{array}$ & $\begin{array}{l}4.090000, \\
6.090000, \\
8.090000\end{array}$ & $\begin{array}{l}1.180000, \\
3.000000, \\
5.000000\end{array}$ & $\begin{array}{l}1.450000 \\
3.360000 \\
5.300006\end{array}$ & $\begin{array}{l}5.550000 \\
7.500005 \\
9.270000\end{array}$ & $\begin{array}{l}1.820000 \\
3.730000 \\
5.730000\end{array}$ \\
\hline T32 & $\begin{array}{l}3.550000 \\
5.550000 \\
7.360000\end{array}$ & $\begin{array}{l}3.730000 \\
5.550000 \\
7.270000\end{array}$ & $\begin{array}{l}2.820000, \\
4.820000, \\
6.730000\end{array}$ & $\begin{array}{l}1.640000 \\
3.550000 \\
5.550000\end{array}$ & $\begin{array}{l}4.270000, \\
6.270000, \\
8.180000\end{array}$ & $\begin{array}{l}1.730000, \\
3.550000, \\
5.550000\end{array}$ \\
\hline $\mathrm{T} 41$ & $\begin{array}{l}4.450000 \\
6.450000, \\
8.180000\end{array}$ & $\begin{array}{l}2.360000 \\
4.270000 \\
6.270000\end{array}$ & $\begin{array}{l}1.200000 \\
3.000000 \\
5.000000\end{array}$ & $\begin{array}{l}1.360000 \\
3.360000 \\
5.360000\end{array}$ & $\begin{array}{l}3.730000 \text {, } \\
5.550000 \text {, } \\
7.270000\end{array}$ & $\begin{array}{l}2.820000, \\
4.820000, \\
6.730000\end{array}$ \\
\hline $\mathrm{T} 42$ & $\begin{array}{l}4.450000 \\
6.450000 \\
8.270000\end{array}$ & $\begin{array}{l}4.820000 \\
6.820000 \\
8.550000\end{array}$ & $\begin{array}{l}1.090000, \\
2.820000, \\
4.820000\end{array}$ & $\begin{array}{l}0.820000 \\
2.640000 \\
4.640000\end{array}$ & $\begin{array}{l}2.360000 \\
4.270000 \\
6.270000\end{array}$ & $\begin{array}{l}1.200000 \text {, } \\
3.000000 \text {, } \\
5.000000\end{array}$ \\
\hline T51 & $\begin{array}{l}5.730000 \\
7.730000 \\
9.270000\end{array}$ & $\begin{array}{l}5.550000 \\
7.500005 \\
9.270000\end{array}$ & $\begin{array}{l}1.820000 \\
3.730000 \\
5.730000\end{array}$ & $\begin{array}{l}1.640000 \\
3.550000 \\
5.550000\end{array}$ & $\begin{array}{l}4.820000 \\
6.820000 \\
8.550000\end{array}$ & $\begin{array}{l}1.090000, \\
2.820000, \\
4.820000\end{array}$ \\
\hline T52 & $\begin{array}{l}5.180000, \\
7.180000 \\
8.820000\end{array}$ & $\begin{array}{l}4.270000 \\
6.270000 \\
8.180000\end{array}$ & $\begin{array}{l}1.730000 \\
3.550000 \\
5.550000\end{array}$ & $\begin{array}{l}1.180000 \\
3.000000 \\
5.000000\end{array}$ & $\begin{array}{l}5.550000 \\
7.500005 \\
9.270000\end{array}$ & $\begin{array}{l}1.820000 \\
3.730000 \\
5.730000\end{array}$ \\
\hline T61 & $\begin{array}{l}4.450000 \\
6.450000 \\
8.180000\end{array}$ & $\begin{array}{l}4.270000 \\
6.270000 \\
8.090000\end{array}$ & $\begin{array}{l}2.910000, \\
4.820000, \\
6.730000\end{array}$ & $\begin{array}{l}2.820000 \\
4.820000 \\
6.730000\end{array}$ & $\begin{array}{l}4.270000, \\
6.270000, \\
8.180000\end{array}$ & $\begin{array}{l}1.730000, \\
3.550000, \\
5.550000\end{array}$ \\
\hline T62 & $\begin{array}{l}6.270000 \\
8.270000 \\
9.450000\end{array}$ & $\begin{array}{l}5.730000 \\
7.730000 \\
9.000000\end{array}$ & $\begin{array}{l}1.640000, \\
3.360000 \\
5.360000\end{array}$ & $\begin{array}{l}1.450000 \\
3.360000 \\
5.360000\end{array}$ & $\begin{array}{l}4.270000, \\
6.270000, \\
8.090000\end{array}$ & $\begin{array}{l}2.910000, \\
4.820000, \\
6.730000\end{array}$ \\
\hline T63 & $\begin{array}{l}4.180000, \\
6.090000, \\
7.640000\end{array}$ & $\begin{array}{l}5.730000 \\
7.730000 \\
9.000000\end{array}$ & $\begin{array}{l}0.820000 \\
2.450000 \\
4.450000\end{array}$ & $\begin{array}{l}1.640000 \\
3.550000 \\
5.550000\end{array}$ & $\begin{array}{l}5.730000 \\
7.730000 \\
9.000000\end{array}$ & $\begin{array}{l}1.640000 \text {, } \\
3.360000 \text {, } \\
5.360000\end{array}$ \\
\hline
\end{tabular}


Table 20: The weighted normalized fuzzy-decision matrix

\begin{tabular}{|c|c|c|c|c|c|c|}
\hline & $\mathrm{A}_{1}$ & $\mathrm{~A}_{2}$ & $\mathrm{~A}_{3}$ & $\mathrm{~A}_{4}$ & $\mathrm{~A}_{5}$ & $\mathrm{~A}_{6}$ \\
\hline T11 & $\begin{array}{l}0.000100 \\
0.000600 \\
0.001900\end{array}$ & $\begin{array}{l}0.002000 \\
0.006000 \\
0.020000\end{array}$ & $\begin{array}{l}0.002000 \\
0.006000 \\
0.020000\end{array}$ & $\begin{array}{l}0.002000 \\
0.006000 \\
0.020000\end{array}$ & $\begin{array}{l}0.001000 \\
0.004000 \\
0.017000\end{array}$ & $\begin{array}{l}0.001000 \text {, } \\
0.005000, \\
0.018000\end{array}$ \\
\hline T12 & $\begin{array}{l}0.000200 \\
0.000800 \\
0.002700\end{array}$ & $\begin{array}{l}0.002000 \\
0.008000 \\
0.025000\end{array}$ & $\begin{array}{l}0.002000 \\
0.008000 \\
0.025000\end{array}$ & $\begin{array}{l}0.002000 \\
0.008000 \\
0.025000\end{array}$ & $\begin{array}{l}0.000000 \\
0.004000 \\
0.017000\end{array}$ & $\begin{array}{l}0.002000, \\
0.007000, \\
0.025000\end{array}$ \\
\hline $\mathrm{T} 21$ & $\begin{array}{l}0.000100 \\
0.000500 \\
0.001800\end{array}$ & $\begin{array}{l}0.002000 \\
0.007000 \\
0.022000\end{array}$ & $\begin{array}{l}0.002000 \\
0.007000 \\
0.022000\end{array}$ & $\begin{array}{l}0.002000 \\
0.007000 \\
0.022000\end{array}$ & $\begin{array}{l}0.000000 \\
0.002000 \\
0.009000\end{array}$ & $\begin{array}{l}0.001000 \text {, } \\
0.005000 \text {, } \\
0.018000\end{array}$ \\
\hline $\mathrm{T} 22$ & $\begin{array}{l}0.000100 \\
0.000600 \\
0.001900\end{array}$ & $\begin{array}{l}0.002000 \\
0.006000 \\
0.020000\end{array}$ & $\begin{array}{l}0.002000 \\
0.006000 \\
0.020000\end{array}$ & $\begin{array}{l}0.002000 \\
0.006000 \\
0.020000\end{array}$ & $\begin{array}{l}0.001000 \\
0.004000 \\
0.017000\end{array}$ & $\begin{array}{l}0.001000 \text {, } \\
0.005000 \text {, } \\
0.018000\end{array}$ \\
\hline $\mathrm{T} 23$ & $\begin{array}{l}0.000200 \\
0.000800 \\
0.002700\end{array}$ & $\begin{array}{l}0.002000 \\
0.008000 \\
0.025000\end{array}$ & $\begin{array}{l}0.002000 \\
0.008000 \\
0.025000\end{array}$ & $\begin{array}{l}0.002000 \\
0.008000 \\
0.025000\end{array}$ & $\begin{array}{l}0.000000 \\
0.004000 \\
0.017000\end{array}$ & $\begin{array}{l}0.002000, \\
0.007000, \\
0.025000\end{array}$ \\
\hline T31 & $\begin{array}{l}0.000200 \\
0.000800 \\
0.002700\end{array}$ & $\begin{array}{l}0.002000 \\
0.008000 \\
0.025000\end{array}$ & $\begin{array}{l}0.002000 \\
0.008000 \\
0.025000\end{array}$ & $\begin{array}{l}0.002000 \\
0.008000 \\
0.025000\end{array}$ & $\begin{array}{l}0.000000 \\
0.004000 \\
0.017000\end{array}$ & $\begin{array}{l}0.002000 \\
0.007000 \\
0.025000\end{array}$ \\
\hline T32 & $\begin{array}{l}0.000100 \\
0.000500 \\
0.001800\end{array}$ & $\begin{array}{l}0.002000 \\
0.007000 \\
0.022000\end{array}$ & $\begin{array}{l}0.002000 \\
0.007000 \\
0.022000\end{array}$ & $\begin{array}{l}0.002000 \\
0.007000 \\
0.022000\end{array}$ & $\begin{array}{l}0.000000 \\
0.002000 \\
0.009000\end{array}$ & $\begin{array}{l}0.001000, \\
0.005000, \\
0.018000\end{array}$ \\
\hline $\mathrm{T} 41$ & $\begin{array}{l}0.000200 \\
0.000800 \\
0.002700\end{array}$ & $\begin{array}{l}0.002000 \\
0.008000 \\
0.025000\end{array}$ & $\begin{array}{l}0.002000 \\
0.008000 \\
0.025000\end{array}$ & $\begin{array}{l}0.002000 \\
0.008000 \\
0.025000\end{array}$ & $\begin{array}{l}0.000000 \\
0.004000 \\
0.017000\end{array}$ & $\begin{array}{l}0.002000, \\
0.007000, \\
0.025000\end{array}$ \\
\hline $\mathrm{T} 42$ & $\begin{array}{l}0.000100 \\
0.000500 \\
0.001800\end{array}$ & $\begin{array}{l}0.002000 \\
0.007000 \\
0.022000\end{array}$ & $\begin{array}{l}0.002000 \\
0.007000 \\
0.022000\end{array}$ & $\begin{array}{l}0.002000, \\
0.007000, \\
0.022000\end{array}$ & $\begin{array}{l}0.000000 \\
0.002000 \\
0.009000\end{array}$ & $\begin{array}{l}0.001000, \\
0.005000, \\
0.018000\end{array}$ \\
\hline T51 & $\begin{array}{l}0.000200 \\
0.000800 \\
0.002700\end{array}$ & $\begin{array}{l}0.002000 \\
0.008000 \\
0.025000\end{array}$ & $\begin{array}{l}0.002000 \\
0.008000 \\
0.025000\end{array}$ & $\begin{array}{l}0.002000 \\
0.008000 \\
0.025000\end{array}$ & $\begin{array}{l}0.000000 \\
0.004000 \\
0.017000\end{array}$ & $\begin{array}{l}0.002000, \\
0.007000, \\
0.025000\end{array}$ \\
\hline T52 & $\begin{array}{l}0.000200 \\
0.000800 \\
0.002700\end{array}$ & $\begin{array}{l}0.002000 \\
0.008000 \\
0.025000\end{array}$ & $\begin{array}{l}0.002000 \\
0.008000 \\
0.025000\end{array}$ & $\begin{array}{l}0.002000 \\
0.008000 \\
0.025000\end{array}$ & $\begin{array}{l}0.000000 \\
0.004000 \\
0.017000\end{array}$ & $\begin{array}{l}0.002000, \\
0.007000, \\
0.025000\end{array}$ \\
\hline T61 & $\begin{array}{l}0.000100 \\
0.000500 \\
0.001800\end{array}$ & $\begin{array}{l}0.002000 \\
0.007000 \\
0.022000\end{array}$ & $\begin{array}{l}0.002000 \\
0.007000 \\
0.022000\end{array}$ & $\begin{array}{l}0.002000, \\
0.007000, \\
0.022000\end{array}$ & $\begin{array}{l}0.000000 \\
0.002000 \\
0.009000\end{array}$ & $\begin{array}{l}0.001000, \\
0.005000, \\
0.018000\end{array}$ \\
\hline T62 & $\begin{array}{l}0.000100 \\
0.000600 \\
0.001900\end{array}$ & $\begin{array}{l}0.002000 \\
0.006000 \\
0.020000\end{array}$ & $\begin{array}{l}0.002000 \\
0.006000 \\
0.020000\end{array}$ & $\begin{array}{l}0.002000 \\
0.006000 \\
0.020000\end{array}$ & $\begin{array}{l}0.001000 \\
0.004000 \\
0.017000\end{array}$ & $\begin{array}{l}0.001000 \text {, } \\
0.005000, \\
0.018000\end{array}$ \\
\hline T63 & $\begin{array}{l}0.000200 \\
0.000800 \\
0.002700\end{array}$ & $\begin{array}{l}0.002000 \\
0.008000 \\
0.025000\end{array}$ & $\begin{array}{l}0.002000 \\
0.008000 \\
0.025000\end{array}$ & $\begin{array}{l}0.002000 \\
0.008000 \\
0.025000\end{array}$ & $\begin{array}{l}0.000000 \\
0.004000 \\
0.017000\end{array}$ & $\begin{array}{l}0.002000, \\
0.007000, \\
0.025000\end{array}$ \\
\hline
\end{tabular}


Table 21: Closeness coefficients to the aspired level among the different alternatives

\begin{tabular}{llllll}
\hline Alternatives & & $\mathrm{d}^{+\mathrm{i}}$ & $\mathrm{d}^{-\mathrm{i}}$ & Gap degree of $\mathrm{CC}^{+\mathrm{i}}$ & Satisfaction degree of $\mathrm{CC}^{-\mathrm{i}}$ \\
\hline Alternative 1 & $\mathrm{A} 1$ & 0.044000 & 0.027000 & 0.37912 & 0.611123 \\
Alternative 2 & $\mathrm{A} 2$ & 0.037000 & 0.036000 & 0.49741 & 0.514115 \\
Alternative 3 & A3 & 0.035000 & 0.041000 & 0.53852 & 0.450254 \\
Alternative 4 & A4 & 0.035000 & 0.027000 & 0.43845 & 0.570025 \\
Alternative 5 & A5 & 0.038000 & 0.046000 & 0.54741 & 0.464526 \\
Alternative 6 & A6 & 0.032000 & 0.048000 & 0.62774 & 0.397884 \\
\hline
\end{tabular}

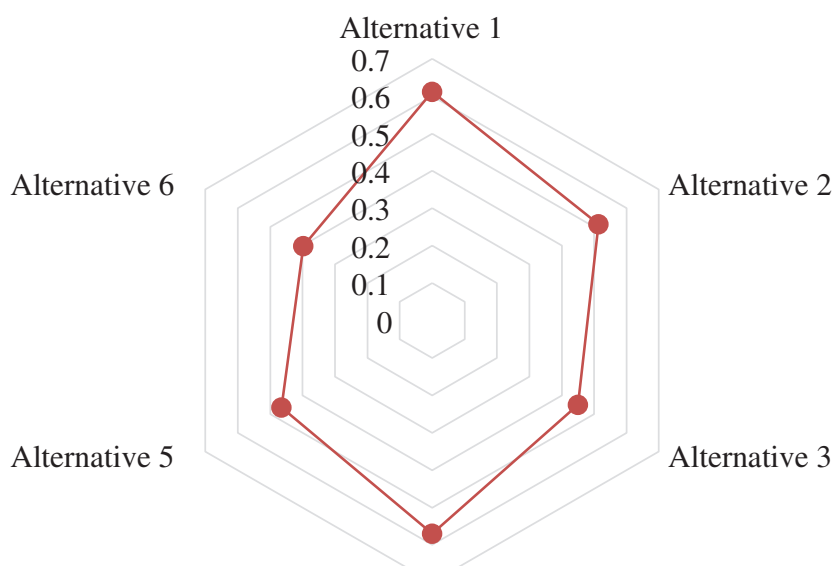

Alternative 4

Figure 6: Graphical representation of satisfaction degree

Table 22: Sensitivity analysis

\begin{tabular}{lllllllll}
\hline Scenario & $\begin{array}{l}\text { Weights/ } \\
\text { Alternatives }\end{array}$ & & A1 & A2 & A3 & A4 & A5 & A6 \\
Exp-0 & $\begin{array}{l}\text { Original } \\
\text { weights }\end{array}$ & $\begin{array}{l}\text { Satisfaction } \\
\text { degree }\end{array}$ & 0.611123 & 0.514115 & 0.450254 & 0.570025 & 0.464526 & 0.397884 \\
Exp-1 & T11 & (CC-1) & 0.637141 & 0.517000 & 0.475000 & 0.572000 & 0.468000 & 0.385000 \\
Exp-2 & T12 & & 0.604547 & 0.490000 & 0.448000 & 0.552000 & 0.443000 & 0.390000 \\
Exp-3 & T21 & & 0.63615 & 0.423000 & 0.385000 & 0.596000 & 0.477000 & 0.344000 \\
Exp-4 & T22 & & 0.609116 & 0.584000 & 0.537000 & 0.528000 & 0.434000 & 0.431000 \\
Exp-5 & T23 & & 0.531745 & 0.505000 & 0.454000 & 0.547000 & 0.451000 & 0.341000 \\
Exp-6 & T31 & & 0.714116 & 0.502000 & 0.468000 & 0.577000 & 0.460000 & 0.434000 \\
Exp-7 & T32 & & 0.711745 & 0.598000 & 0.562000 & 0.564000 & 0.456000 & 0.521000 \\
Exp-8 & T41 & & 0.534774 & 0.409000 & 0.360000 & 0.559000 & 0.455000 & 0.255000 \\
Exp-9 & T42 & & 0.559885 & 0.450000 & 0.422000 & 0.529000 & 0.494000 & 0.320000 \\
Exp-10 & T51 & & 0.685745 & 0.557000 & 0.500000 & 0.595000 & 0.417000 & 0.455000 \\
Exp-11 & T52 & & 0.665745 & 0.539000 & 0.485000 & 0.581000 & 0.400000 & 0.418000 \\
Exp-12 & T61 & & 0.580444 & 0.468000 & 0.438000 & 0.543000 & 0.511000 & 0.358000 \\
Exp-13 & T62 & & 0.592000 & 0.481000 & 0.428000 & 0.529000 & 0.423000 & 0.381000 \\
Exp-14 & T63 & & 0.652000 & 0.526000 & 0.494000 & 0.595000 & 0.488000 & 0.394000 \\
\hline
\end{tabular}


Table 23: Comparison the results

\begin{tabular}{lllllll}
\hline Methods/Alternatives & A1 & A2 & A3 & A4 & A5 & A6 \\
\hline Fuzzy-AHP-TOPSIS method & 0.611123 & 0.514115 & 0.450254 & 0.570025 & 0.464526 & 0.397884 \\
Fuzzy-ANP-TOPSIS method & 0.612000 & 0.514000 & 0.451000 & 0.572000 & 0.465000 & 0.398000 \\
Fuzzy Weighted Average method & 0.625620 & 0.515480 & 0.457980 & 0.572510 & 0.459200 & 0.398580 \\
Classical-AHP-TOPSIS method & 0.615470 & 0.514710 & 0.462460 & 0.553570 & 0.461480 & 0.387890 \\
Classical-AHP-TOPSIS method & 0.624570 & 0.511260 & 0.460030 & 0.560090 & 0.462590 & 0.389920 \\
\hline
\end{tabular}

To make the evaluation process more significant and to identify whether the adopted methodology is appropriate or not, the authors compared the results from various other similar technologies. To make the comparison effective and efficient, the authors chose 4 similar methodologies and compared the results of all methodologies for the same parameters. The authors evaluated the same resources and criteria's from different selected methodologies get results for comparison. The results are discussed in Tab. 23 that shows that the most effective results are obtained from adopted fuzzy-AHP-TOPSIS methodology and the ratio of difference in all the mythologies is not too much. This proves the efficiency of the methodology as well.

\section{Discussion}

Today's healthcare data is highly valuable and that is the key reason for the vulnerability of the data. The Healthcare sector is the most exciting field where blockchain is set to change the medical care environment. Major advancements in this league include the protection of EHRs and the historiography of medicine. Blockchain technology is revolutionizing the healthcare sector by taking all of the valuable healthcare data to one platform for concerned parties to access and operate in a manner that any changes introduced in the record by one participant become visible to all those in the framework. This technological innovation is presented by the integration of blockchain as well as Healthcare infrastructure. Blockchain technology's specific features such as decentralization, Immutability, as well as security, incorporate to overcome a range of important issues facing the healthcare sector currently. A report on breach episodes cites that, approximately, 1.4 data breach incidents happened every day in 2019 [33].

Making EMR process more secure and safe for Saudi Arabian healthcare organizations is the most significant goal of researchers. The proposed paper is an initial milestone in achieving this goal and provide a significant role in enabling blockhcain as a security option for experts. The evaluated effectiveness of blockchain methodology in this paper in a data security perspective of healthcare has a vast scope and gives an effective pathway for security experts. Further, in order to achieve this computational outcome that blockchain is effective authors perform a numerical simulation by adopting MCDM approach named fuzzy-AHP-TOPSIS that enables them to examine the effectiveness of identified criteria's on the basis of quantitative measurements. Overall results of our research work (both pros and limitations) are:

\subsection{Pros}

The biggest benefit of this study is its recommendation and the trending topic of simulation that can be a milestone in the context of using blockchain technology for security and protecting the integrity and privacy of the healthcare data in the Kingdom of Saudi Arabia. According to 
the recommendation of this study, the engineers can adopt the factors of blockchain for achieving effective security of the digital healthcare services.

\subsection{Limitations}

Due to the complex nature of the healthcare services, the blockchain technology is still in its nascent stage; hence more empirical base is required to be highly conclusive and emphatic about the proposed mechanism. There are many other MCDM approaches available in technology and the evaluation of their effect by many integration methods is still awaited, so this is also a limitation of ours study.

\section{Conclusions}

The current health crisis of COVID-19 pandemic requires highly secure, breach-proof management of healthcare data in all countries of the world. The present study is an attempt to facilitate this task in the KSA in ensuring effective, prompt and safe healthcare service management. The study recommends a systematic and convenient pathway for integrating blockchain with healthcare data security in KSA. The article proposes a MCDM approach named integrated fuzzy-AHP-TOPSIS approach for simulating the blockchain impact and it also discuss the results of evaluation in logical terms. It has been concluded that alternative (A1) offers the most robust protection mechanism among all the six successful alternatives Based on these evaluations, the results of the study can be used as a template by any designer for planning a time saving and cost-effective approach for efficient implementation of the blockchain technology.

Acknowledgement: This research work was funded by the Institutional Fund Projects under the Grant No. (IFPHI-264-611-2020). The authors are grateful for the technical and financial support rendered to them by the Ministry of Education and King Abdulaziz University, DSR, Jeddah, Saudi Arabia.

Funding Statement: Funding for this study was received from the Ministry of Education and Deanship of Scientific Research at King Abdulaziz University, Kingdom of Saudi Arabia under the Grant No. IFPHI-264-611-2020.

Conflicts of Interest: The authors declare that they have no conflicts of interest to report regarding the present study.

\section{References}

[1] M. Gorodnichev, A. Kukharenko, E. Kukharenko and T. Salutina, "Methods of developing systems based on blockchain," in Proc. of the 24th Conf. of Open Innovations Association FRUCT, Helsinki, Uusimaa, Finland, pp. 613-618, 2019.

[2] T. Nugent, D. Upton and M. Cimpoesu, "Improving data transparency in clinical trials using blockchain smart contracts," F1000Research, vol. 5, no. 5, pp. 2541-2549, 2016.

[3] M. Crosby, P. Pattanayak, S. Verma and V. Kalyanaraman, "Blockchain technology: Beyond bitcoin," Applied Innovation, vol. 71, no. 2, pp. 6-10, 2016.

[4] Z. Zheng, S. Xie, H. N. Dai, X. Chen and H. Wang, "Blockchain challenges and opportunities: A survey," International Journal of Web and Grid Services, vol. 14, no. 4, pp. 352-375, 2018.

[5] M. Andoni, V. Robu, D. Flynn, S. Abram, D. Geach et al., "Blockchain technology in the energy sector: A systematic review of challenges and opportunities," Renewable and Sustainable Energy Reviews, vol. 100, no. 5, pp. 143-174, 2019. 
[6] B. Teufel, A. Sentic and M. Barmet, "Blockchain energy: Blockchain in future energy systems," Journal of Electronic Science and Technology, vol. 1, no. 1, pp. 100-111, 2020.

[7] M. Li, S. Shao, Q. Ye, G. Xu and G. Q. Huang, "Blockchain-enabled logistics finance execution platform for capital-constrained e-commerce retail," Robotics and Computer-Integrated Manufacturing, vol. 65 , no. 9, pp. 1019-1027, 2020.

[8] F. Damico, "How technology is reshaping financial services: Blockchain use cases in the banking industry," Symmetry, vol. 10, no. 3, pp. 352-375, 2020.

[9] S. Olnes, J. Ubacht and M. Janssen, "Blockchain in government: Benefits and implications of distributed ledger technology for information sharing," Government Information Quarterly, vol. 34, no. 3, pp. 355-364, 2017.

[10] P. Zhang and M. N. K. Boulos, "Blockchain solutions for healthcare," Precision Medicine for Investigators, Practitioners and Providers, vol. 10, no. 13, pp. 519-524, 2020.

[11] P. P. Ray, D. Dash, K. Salah and N. Kumar, "Blockchain for IoT-based healthcare: Background, consensus, platforms, and use cases," IEEE Systems Journal, vol. 1, no. 2, pp. 6-10, 2020.

[12] A. Alammary, S. Alhazmi, M. Almasri and S. Gillani, "Blockchain-based applications in education: A systematic review," Applied Sciences, vol. 9, no. 12, pp. 1-21, 2019.

[13] H. Xiong, T. Dalhaus, P. Wang and J. Huang, "Blockchain technology for agriculture: Applications and rationale," Frontiers in Blockchain, vol. 3, no. 7, pp. 21-51, 2020.

[14] M. Z. A. Bhuiyan, A. Zaman, T. Wang, G. Wang, H. Tao et al., "Blockchain and big data to transform the healthcare," in Proc. of the Int. Conf. on Data Processing and Applications, Guangdong, China, pp. 62-68, 2018.

[15] K. D. Mandl, D. Markwell, R. MacDonald, P. Szolovits and I. S. Kohane, "Public standards and patients' control: How to keep electronic medical records accessible but private," Information in Practice, vol. 322, no. 7281, pp. 283-287, 2001.

[16] C. Arsene, "The global 'blockchain in healthcare' report: The 2020 ultimate guide for every executive," Healthcare Weekly, 2020. [Online]. Available: https://healthcareweekly.com/blockchain-in-healthcareguide/.

[17] R. Kumar, A. K. Pandey, A. Baz, H. Alhakami, W. Alhakami et al., "Fuzzy-based symmetrical multi-criteria decision-making procedure for evaluating the impact of harmful factors of healthcare information security," Symmetry, vol. 12, no. 4, pp. 1-24, 2020.

[18] H. Abusaaq, "Kingdom of Saudi Arabia 2020 budget report," KPMG Professional Services, 2019. [Online]. Available: https://home.kpmg/sa/en/home/insights/2019/12/kingdom-of-saudi-arabia-2020budget-report.html.

[19] X. Yue, H. Wang, D. Jin, M. Li and W. Jiang, "Healthcare data gateways: found healthcare intelligence on blockchain with novel privacy risk control," Journal of Medical Systems, vol. 40, no. 10, pp. 1-25, 2016.

[20] R. Kumar, A. I. Khan, Y. B. Abushark, M. M. Alam, A. Agrawal et al., "An integrated approach of fuzzy logic, AHP and TOPSIS for estimating usable-security of web applications," IEEE Access, vol. 8, no. 4, pp. 50944-50957, 2020.

[21] İ. Ertuğrul and N. Karakaşoğlu, "Comparison of fuzzy AHP and fuzzy TOPSIS methods for facility location selection," The International Journal of Advanced Manufacturing Technology, vol. 39, no. 8, pp. 783-795, 2008.

[22] X. Liang, J. Zhao, S. Shetty, J. Liu and D. Li, "Integrating blockchain for data sharing and collaboration in mobile healthcare applications," in Proc. of the 2017 IEEE 28th Annual Int. Sym. on Personal, Indoor, and Mobile Radio Communications, Montreal, QC, Canada, pp. 1-5, 2017.

[23] X. Zheng, A. V. Campos, J. O. Meré, J. Balseiro and S. L. Marcos, "Continuous monitoring of essential tremor using a portable system based on smartwatch," Frontiers in Neurology, vol. 8, no. 96, pp. 1-20, 2017.

[24] L. Malina, J. Hajny, P. Dzurenda and S. Ricci, "Lightweight ring signatures for decentralized privacypreserving transactions," in Proc. of the 15th Int. Joint Conf. on e-Business and Telecommunications, Porto, Portugal, vol. 2, pp. 692-697, 2018. 
[25] B. M. Till, A. W. Peters, S. Afshar and J. G. Meara, "From blockchain technology to global health equity: Can cryptocurrencies finance universal health coverage?," BMJ Global Health, vol. 2, no. 4, pp. $1-21,2017$.

[26] M. A. Rahman, A. Elsaddik and W. Gueaieb, "Building dynamic social network from sensory data feed," IEEE Transactions on Instrumentation and Measurement, vol. 59, no. 5, pp. 1327-1341, 2010.

[27] M. Tavana, F. Zandi and M. N. Katehakis, "A hybrid fuzzy group AHP-TOPSIS framework for assessment of e-government readiness from a CiRM perspective," Information \& Management, vol. 50, no. 7, pp. 383-397, 2013.

[28] F. A. Nouri, S. K. Esbouei and J. Antucheviciene, "A hybrid MCDM approach based on fuzzy AHP and fuzzy TOPSIS for technology selection," Informatica, vol. 26, no. 3, pp. 369-388, 2015.

[29] R. J. Kuo, C. W. Hsu and Y. L. Chen, "Integration of fuzzy AHP and fuzzy TOPSIS for evaluating carbon performance of suppliers," International Journal of Environmental Science and Technology, vol. 12, no. 12 , pp. 3863-3876, 2015.

[30] B. C. Ervural, S. Zaim, O. F. Demirel, Z. Aydin and D. Delen, "An AHP and fuzzy TOPSIS-based SWOT analysis for Turkey's energy planning," Renewable and Sustainable Energy Reviews, vol. 82, no. 5, pp. $1538-1550,2018$.

[31] A. Abbaspour, M. Saremi, A. Alibabaei and P. S. Moghanlu, "Determining the optimal human reliability analysis (HRA) method in healthcare systems using fuzzy AHP and fuzzy TOPSIS," Journal of Patient Safety and Risk Management, vol. 8, no. 6, pp. 1-20, 2020.

[32] M. Zarour, M. T. J. Ansari, M. Alenezi, A. K. Sarkar, M. Faizan et al., "Evaluating the impact of blockchain models for secure and trustworthy electronic healthcare records," IEEE Access, vol. 8, pp. 157959-157973, 2020.

[33] W. Alhakami, A. Baz, H. Alhakami, A. K. Pandey and R. A. Khan, "Symmetrical model of smart healthcare data management: A cybernetics perspective," Symmetry, vol. 12, no. 12, pp. 1-18, 2020. 